\title{
Editorial
}

\section{Administrative Sciences Introduces Double Blind Peer-Review}

\author{
Martyn Rittman ${ }^{1}$ and Joseph Roberts ${ }^{2}$ \\ 1 MDPI AG, Klybeckstrasse 64, CH-4057 Basel, Switzerland; E-Mail: rittman@mdpi.com \\ 2 George Herbert Walker School of Business \& Technology, Webster University, St. Louis, \\ MO 63119, USA; E-Mail: joeroberts@webster.edu
}

Received: 1 June 2015; Published: 1 June 2015

\section{Introduction}

Peer-review has become, and remains, the cornerstone on which scientific publication is built. Despite criticism, it remains almost the only method by which acceptance into the corpus of research literature is based.

Single blind peer-review remains the most popular, in which the authors of submitted articles do not know the identity of the reviewers, however the reviewers do know the authors. In double blind peer-review, neither the authors nor the reviewers know each other's identity during the review process. Unblinded versions of peer-review also exist, where authors and reviewers are known to each other from the outset.

Until now, Administrative Sciences has operated a single blind peer-review process, in common with other MDPI journals. This is the standard used in scientific journals, however in fields such as business and economics double blind peer-review has become the norm. Keeping with best practices, we are implementing a double peer-review process in Administrative Sciences.

The advantages of a double blind process are that it removes bias by reputation or prejudice, bringing benefits to women, junior authors, and those from countries or institutions without a high research profile.

Some readers may be disappointed about a move away from more openness and transparency. However, this is not necessarily the case. MDPI's journal Life offers open peer review, where authors can choose to have review reports published and reviewers can choose to reveal their identity with the published review reports. Such a process is not compromised by the introduction of double blind peer-review and both can run alongside each other. We also believe that a double blind review process will provide professional development opportunities and better serve junior faculty and researchers 
effectively. In fact, Administrative Sciences will also be offering the open review option to authors. In this way we can make the editorial process both fairer and more transparent.

Double blind peer-review will be introduced for all articles submitted from today. This means that any article with a received date of 1 June 2015 or later will undergo a double blind review process. Technical details on the preparation of manuscripts can be found on the journal's instructions for authors page, at http://www.mdpi.com/journal/admsci/instructions.

\section{Conflicts of Interest}

The authors declare no conflict of interest.

(C) 2015 by the authors; licensee MDPI, Basel, Switzerland. This article is an open-access article distributed under the terms and conditions of the Creative Commons Attribution license (http://creativecommons.org/licenses/by/4.0/). 